\title{
Work motivation and occupational self-efficacy belief to continue working among ageing home care nurses: a qualitative study with a mixed methods approach
}

Stina Wallin ( $\nabla$ stina.wallin@abo.fi )

Åbo Akademi University

Anncristine Fjellman-Wiklund

Umeå University

Lisbeth Fagerström

Åbo Akademi University

\section{Research Article}

Keywords: ageing workers, home health aides, occupational health, healthy ageing, personal resources, occupational self-efficacy, work motivation, mixed methods

Posted Date: May 5th, 2021

DOI: https://doi.org/10.21203/rs.3.rs-450587/v1

License: (c) (1) This work is licensed under a Creative Commons Attribution 4.0 International License.

Read Full License 


\section{Abstract}

Background: It is important to support ageing home care nurses (HCNs) to remain in work for longer, since the need for home care services is increasing. Personal resources such as self-efficacy belief contribute to work ability, as does work motivation. Few studies have targeted the ageing workers' selfefficacy belief to manage their final working years. This study explores ageing HCNs' work motivation, and occupational self-efficacy, i.e. belief in one's capabilities, to continue working until expected retirement age.

Methods: This exploratory qualitative study, analysed with a mixed methods approach, reports on phase two of a cross-sectional survey. A total of $234 \mathrm{HCNs}$ answered four open-ended questions, regarding their work motivation and self-efficacy beliefs. First, data was analysed using manifest qualitative content analysis. Next, a quantitative analysis was performed based on the results of the qualitative study, and the categories that emerged were quantitatively ranked.

Results: The open-ended questions yielded 2339 utterances. The findings showed that several factors concurrently affected both work motivation and self-efficacy belief. When the factors were wellfunctioning, they positively affected both motivation and self-efficacy belief, and when they were insufficient, they negatively affected either or both motivation and/or belief. Meaningfulness, job satisfaction, social support, and work environmental and organizational characteristics affected work motivation most. Perceived health highly affected the self-efficacy belief to continue working until expected retirement age, as well as meaningfulness of work, support from colleagues and supervisors, and work characteristics.

Conclusions: Through highlighting the meaningfulness of work, and supporting the perceived health, the work community and leadership, both work motivation and self-efficacy belief to continue working might be facilitated among ageing HCNs. However, the still present draining workload must be focused.

\section{Background}

In home health care, workers are the greatest resource since a lack of workers means limited service (1). In many countries the supply of home care services has increased or aim to increase $(1 ; 2 ; 3)$ as a consequence of that the European population is getting older (4), and that the need for care is expected to escalate because of the growing number of older people (4). One reason for this is that most people prefer to remain in their homes $(1 ; 2 ; 3)$, and that the potential for informal family care is decreased due to prolonged employment and changed family structures $(1 ; 2)$. Additionally, old people maintain their functional ability better when they are staying in their homes. Home care is also a cheaper alternative to institutional care $(1 ; 2)$. Home care work usually entails day-to-day assistance and nursing to help clients cope with their everyday needs and activities (5). However, an already existing challenge is the shortage of staff $(2 ; 6)$, and about $40 \%$ of HCNs in the Nordic countries have considered quitting their work $(5 ; 7)$. Reasons for this are the unfavourable working conditions (2), and an increased physical and mental 
workload $(3 ; 5)$ caused of an increased number of clients, more complex clients and less personnel $(3)$. HCNs have expressed concerns about both the quality of home care and the safety of the clients $(5 ; 3)$, as well as their own health (5). However, HCNs still experience meaningfulness of work (5).

The importance of HCNs' motivation for maintaining home care services (1), and for the quality of healthcare (8) has been emphasized. Additionally, work motivation contributes to work ability among home care aides (9) and nurses (8). Although there is no unambiguous definition of nurses' work motivation, it refers to the accomplishment of tasks as well as the desire to do work (8). Nurses' work motivation is individually created and affected by both personal internal factors and external work-related factors. Universally, work motivation does not decline with age, as considered by former negative stereotypes (10). Intrinsic motivation, i.e. performing an activity for its own sake in order to achieve satisfaction (11), is a key to continue working until retirement age (12). Ageing workers seems to be more motivated by intrinsic aspects (13), such as meaning of work for example $(12 ; 10 ; 14 ; 15 ; 5)$. Earlier studies have stressed the importance to focus on factors that motivates ageing workers to stay in work (16), as well as on on strategies enhancing intrinsic motivation (17). Since factors influencing work motivation may differ in different cultures and contexts of nursing practice (8), we venture to say that work motivation also should be explored in the specific context of ageing HCNs.

Another aspect of the ageing population is the decreasing numbers of young workers, which has stressed the importance of retaining ageing workers in working life (18). As a fact, a large percentage of home care staff is also ageing $(7 ; 5)$. Although there is a large different between individuals, the occurrence of chronic health problems generally increases with higher age, and with more older workers the prevalence of workers with health problems escalates (19). Work ability is strongly related to health (20). Chronic health problems in ageing workers tend to decrease their work ability and increase an early exit from work (21). Moreover, work ability generally tends to decrease with age (20), explained by the imbalance between individual resources and job demands (22). Practices supporting ageing workers are mostly focusing on reducing job demands and increasing job resources, and seldom on enhancing personal resources (23). However, previous research has shown the value of personal resources, referred to an individuals' sense of whether they can control and influence their environment successfully (24). When personal resources are high, workers are confident about their capabilities, more resilient and optimistic about their future (24). Personal resources might help workers be more resistant against adverse work demands (24), and may together with job resources moderate the negative effects of age on work ability (15).

Self-efficacy is an important personal resource contributing to work ability in home care staff (9), intrinsic motivation (25) in ageing workers (26), and to wellbeing at work $(27 ; 24)$. Occupational self-efficacy refers specifically to the occupational domain. It describes belief in one's capabilities to successfully perform the tasks involved in one's work in respect to occupational adjustment and the management of obstacles (28). Occupational self-efficacy enhances self-regulation of motivation through outcome expectations, goal attainment, and perceived causes of success and failure (29). Previous research has stressed the importance of enhancing self-efficacy in workplace interventions, alongside job resources and job 
demands (9), also for older workers $(26 ; 30)$. Despite much research on self-efficacy in general, less is known about the role that occupational self-efficacy plays for the ageing work force (26), as well as few studies have targeted the ageing workers' personal resources (23). However, a recent study found that occupational self-efficacy was related to ageing HCNs' work ability (31). To enhance occupational selfefficacy in ageing HCNs, it is therefore important to explore factors that influence occupational selfefficacy belief to continue working.

The aim of this mixed methods study is to explore the ageing HCNs' work motivation and occupational self-efficacy, i.e. belief in one's capabilities, to continue working until expected retirement age.

The research questions are:

What positive and negative factors do ageing HCNs' express that affect their work motivation and occupational self-efficacy belief to continue working until expected retirement age?

\section{Methods}

\subsection{Study design}

The design of the study is exploratory and qualitative with a mixed method approach (32).

\subsection{Setting, data collection and participants}

The study is part of the larger research project "Personal resources supporting work ability", aiming to provide knowledge about ageing workers' personal resources during their final working years. In this study, we considered ageing workers 45 years and older, to increase the possibility for preventive measures (33). The survey was carried out in May to September 2018 and was sent to both HCNs and engineers. The questionnaire included three well-reputed, valid, and reliable measuring scales and four open-ended questions, which were analysed separately in two different phases. The results from the measuring scales Work Ability Index (WAI) (34), Utrecht Work Engagement Scale (UWES-9)(35) and Occupational Self-Efficacy Scale - Short Form (OSS-SF)(28) are presented elsewhere (accepted, not yet published).

The HCNs' answers from the open-ended questions composed the source of this study. An English translation of the open-ended questions is provided as Additional File 1. From a region of Western Finland with mostly rural areas, HCNs were recruited using their supervisors. Eight municipalities and cities, conducting home care services by themselves, and two social- and health services consortiums consisting of three to four municipalities or cities each were included. All HCNs, 45 years and older, were recruited to answer an anonymous paper-based or web-based questionnaire available in Swedish or Finnish languages. In the open-ended questions, the HCNs were asked to mention three factors that positively affect and three factors that negatively affect their work motivation, and correspondingly that positively and negatively affect their beliefs in their capabilities (i.e. self-efficacy) to continue working until the expected retirement age (Fig. 1). 
Out of 460 invited participants, $234 \mathrm{HCNs}$ answered the questionnaire after three reminders, yielding a response rate of $51 \%$. Participants were $45-66$ years old, and the majority were women with an average of 18 years work experience in home care (Table 1). Two thirds of the participants had averagely good work ability. 
Table 1

Characteristics of the study population $(n=234)$

\begin{tabular}{|c|c|}
\hline Age (years) & $55(55), 5.3$ \\
\hline $45-49$ & 19.4 \\
\hline $50-54$ & 26.6 \\
\hline $55-59$ & 31.1 \\
\hline $60-66$ & 23.0 \\
\hline \multicolumn{2}{|l|}{ Gender } \\
\hline Women & 99.1 \\
\hline Men & 0.9 \\
\hline \multicolumn{2}{|l|}{ Marital status } \\
\hline Single & 8.3 \\
\hline Married/marriage-like relationship & 80.3 \\
\hline Divorced & 11.0 \\
\hline Widow & 0.4 \\
\hline \multicolumn{2}{|l|}{ Native language } \\
\hline Swedish & 57.3 \\
\hline Finnish & 42.7 \\
\hline \multicolumn{2}{|l|}{ Educational level } \\
\hline No vocational training & 2,7 \\
\hline Vocational degree & 65,5 \\
\hline Higher vocational education & 28,3 \\
\hline Master's degree or higher education & 3,5 \\
\hline \multicolumn{2}{|l|}{ Employment status } \\
\hline Permanent employment & 88.3 \\
\hline Temporary employment & 11.7 \\
\hline Full-time employment & 73.0 \\
\hline Part-time employment & 27.0 \\
\hline \multicolumn{2}{|l|}{ Job demands } \\
\hline Mentally demanding & 18.5 \\
\hline
\end{tabular}




\begin{tabular}{|l|ll|}
\hline \multicolumn{1}{|l|}{ Age (years) } & $\mathbf{5 5}(\mathbf{5 5}), \mathbf{5 . 3}$ \\
\hline Physically demanding & 5.6 \\
\hline Mentally and physically demanding & 75.9 \\
\hline Work experience (years) & $18(18), 12.1$ \\
\hline Work ability index & $38(40), 6.8$ \\
\hline Occupational self-efficacy & $5.9(6.0), 0.8$ \\
\hline Work engagement & $5.1(5.3), 0.9$ \\
\hline & The numbers are either \% or mean (median), standard deviation \\
\cline { 2 - 2 } \\
2.3. Data analysis
\end{tabular}

A mixed methods approach was used, including qualitative and quantitative research $(32 ; 36)$. Using mixed methods enables a better understanding of the complex topic, using the strength of integrating both qualitative and quantitative analyses to generate new knowledge. First, the answers from the openended questions were analysed by qualitative manifest content analysis, to gain a deeper knowledge and understanding $(32 ; 37)$ of ageing $\mathrm{HCNs}^{\prime}$ work-related motivation and occupational self-efficacy belief. Answers from the open-ended questions were organised in Microsoft Excel, with answers from each participant in a separate row. To become familiar with the text, all responses were read through several times. From each question, responses were grouped into topics. Further, for each individual question, the topics were analysed by manifest qualitative content analysis. The condensed text was coded, and the codes were interpreted and compared repeatedly for similarities and differences. Codes with similar content were sorted into sub-sub-categories and sub-categories. Finally, sub-categories were sorted into categories that corresponded to the meaning of the material, the context, and the aim. To confirm conformability, investigator triangulation was used. SW made the initial analysis of the responses into similar topics and condensed the text. In addition to SW, AFW and LF read the condensed answers and the codes independently, and the codes were compared and discussed until agreement was reached (32; 37). Next, a quantitative analysis was performed based on the results of the qualitative study. The categories emerged from the qualitative analysis, referred to as factors, were quantitatively ranked, based on the frequencies of which they were mentioned in all the data for each open-ended question (32). Reporting the frequencies and percentages enabled examination of where the main point in 'HCNs' responses was located in the large amount of data (2339 utterances from the four questions taken together). An integration of both the qualitative and the quantitative approach was used, in the aim, the data analysis, results and discussion $(32 ; 36)$.

\section{Results}

The analysis resulted in seven categories describing factors that affect HCNs' work motivation positively, and ten categories negatively affecting work motivation. Eight categories emerged describing factors 
positively affecting occupational self-efficacy belief to continue working until expected retirement age, and ten categories negatively affecting self-efficacy belief. There were 659 utterances related to factors positively affecting work motivation $(n=225,96 \%)$, and 620 utterances negatively affecting work motivation ( $n=227 ; 97 \%$ ). Regarding factors positively affecting occupational self-efficacy belief to continue working until expected retirement age, 553 utterances were emphasized ( $n=218 ; 93 \%)$, while 507 utterances were related to negatively affecting belief $(n=202 ; 86 \%)$. Typically, the participants gave between one to three responses for each question. For each individual question, the categories that gathered the most utterances, and their sub-categories, are presented more closely below as factors reflecting each research question. The results of the qualitative content analysis, including quotations, are presented in Table 2, and the frequencies of the factors for each question are presented in Fig. 2. 
Table 2

Results of the qualitative content analysis

\section{Factors positively affecting work motivation}

$n=225$ (96\%), 659 utterances

\begin{tabular}{|c|c|c|}
\hline Categories & Sub-categories & Quotations \\
\hline $\begin{array}{l}\text { Work } \\
\text { environment }\end{array}$ & $\begin{array}{l}\text { Satisfaction with } \\
\text { colleagues }\end{array}$ & \multirow{2}{*}{$\begin{array}{l}\text { being with coworkers [makes me feel good] } \\
\text { wonderful workmates and the cooperation we have } \\
\text { good and supportive work team } \\
\text { have influence over own work, can affect } \\
\text { to have a good supervisor, who listens etc. }\end{array}$} \\
\hline $\begin{array}{l}\text { (234 } \\
\text { utterances) }\end{array}$ & $\begin{array}{l}\text { Satisfaction with } \\
\text { leadership and } \\
\text { organizational resources }\end{array}$ & \\
\hline \multirow{2}{*}{$\begin{array}{l}\text { Significance } \\
\text { of the work } \\
\text { (161 } \\
\text { utterances) }\end{array}$} & Meaningful work & \multirow{2}{*}{$\begin{array}{l}\text { "experience that the work is important" } \\
\text { the feeling that you make a difference in the elderly's } \\
\text { everyday life } \\
\text { to get to work with elderly people } \\
\text { get so much back from the clients }\end{array}$} \\
\hline & $\begin{array}{l}\text { Enriching client } \\
\text { meetings }\end{array}$ & \\
\hline \multirow{2}{*}{$\begin{array}{l}\text { Stimulating } \\
\text { challenges } \\
\text { (131 } \\
\text { utterances) }\end{array}$} & Multifaceted work & \multirow{2}{*}{$\begin{array}{l}\text { it isn't monotonous work, something happens all the } \\
\text { time } \\
\text { work independently, must make own decisions } \\
\text { challenging, requires physical and mental fitness as } \\
\text { well as social skills } \\
\text { I feel I can do my job } \\
\text { opportunity to develop, learn new things }\end{array}$} \\
\hline & $\begin{array}{l}\text { Competence and desire } \\
\text { to develop }\end{array}$ & \\
\hline $\begin{array}{l}\text { External } \\
\text { response }\end{array}$ & $\begin{array}{l}\text { Recognition from clients } \\
\text { and relatives }\end{array}$ & $\begin{array}{l}\text { gratitude from clients and relatives } \\
\text { when a client thanks [you] for the help and is satisfied } \\
\text { with the care }\end{array}$ \\
\hline $\begin{array}{l}\text { (77 } \\
\text { utterances) }\end{array}$ & $\begin{array}{l}\text { Recognition from } \\
\text { colleagues and } \\
\text { management }\end{array}$ & $\begin{array}{l}\text { positive feedback from coworkers } \\
\text { appreciation from superiors }\end{array}$ \\
\hline
\end{tabular}

Factors negatively affecting work motivation

$n=227$ (97\%), 620 utterances

Categories Sub-categories Quotations

Organizational Lacking resources

work

environment Unsatisfactory

(176

leadership

utterances)

Time

constraints

(144

utterances)
Significant rush and stress

Negative consequences of time pressure not equipment to get the job done

one should constantly take in so many darn new things existing knowledge is not utilized if superiors don't listen or don't care unappreciative head nurse, only hear how bad we are poor management - don't understand our job

hurry, tight work schedules that others plan not knowing whether you have time to eat during the work day

lack of time [with] the clients, just in a hurry all the time the lack of time - not having the time to perform one's tasks

things that are left unfinished 


\section{Factors positively affecting work motivation}

\section{$n=225$ (96\%), 659 utterances}

$\begin{array}{ll}\text { Job } & \text { A hard work } \\ \text { characteristics } & \text { Lowered ambition }\end{array}$

$(119$ utterances)

change of clients, that you are not allowed to care for the same clients but are instead forced to change daily = IRRITATING home care clients are becoming more and more complex, and everything should be documented wintertime when the roads are icy, poorly plowed, and early spring with poor road conditions would like to continue to educate myself at regular intervals but it's difficult to manage with full-time job little possibility to influence decisions, even though I, for example, know something better than those who decide

It is not always so fun

Work Negative atmosphere

community

(74

Poor engagement

utterances) bad atmosphere among the personnel gossip, mean talk behind your back poor work ethic among colleagues if you can't trust your workmates (that the work has been done)

Factors positively affecting occupational self-efficacy belief to continue working until expected retirement age

$\mathrm{n}=218$ (93\%), 553 utterances

$\begin{array}{lll}\text { Categories } & \text { Sub-categories } & \text { Quotations } \\ \text { Own health } & \begin{array}{l}\text { A resource and a } \\ \text { challenge }\end{array} & \begin{array}{l}\text { if [my] health stays the same as now, it will be ok } \\ \text { you don't know whether you are capable until } \\ \text { retirement because of the workload }\end{array} \\ \begin{array}{l}\text { I } 140 \\ \text { utterances })\end{array} & \begin{array}{l}\text { Health supporting take care of myself so that I am capable } \\ \text { activities }\end{array} & \begin{array}{l}\text { hope to be able to improve [my] work ability } \\ \text { hom }\end{array}\end{array}$

Workplace resources

Satisfactory organizational resources

(118 utterances) Strong workplace community

Meaning of the work

(97

Satisfaction from work

Intrinsic motivation

utterances)

Nature of the Job stability work

(94 Skilled in demanding work support and encouragement from my supervisor that the employer recognizes age in a positive way the support from work colleagues our fine sense of community in the work team utterances)

successful client meetings

[I] enjoy my work tasks

[i] like to help people

the feeling of making a difference

love for my own work

there are always sick people

home care is also needed in the future

I don't feel old, I still want to learn new things master different situations

that the work pace shouldn't be pushed to the breaking point 


\section{Factors positively affecting work motivation \\ $n=225$ (96\%), 659 utterances}

Factors negatively affecting occupational self-efficacy belief to continue working until expected retirement age

$\mathrm{n}=202(86 \%), 507$ utterances

$\begin{array}{lll}\text { Categories } & \text { Sub-categories } & \text { Quotations } \\ \begin{array}{ll}\text { Health-related } \\ \text { decline }\end{array} & \begin{array}{l}\text { Current life and health } \\ \begin{array}{l}\text { (145 } \\ \text { utterances) }\end{array}\end{array} & \begin{array}{l}\text { Future health challenges is no such thing, unless [my] health fails } \\ \text { the pain that is getting worse } \\ \text { that [my] body is not capable of the work } \\ \text { Idon't know if I am capable of 'running' to the end, } \\ \text { probably not }\end{array}\end{array}$

$\begin{array}{lll}\begin{array}{l}\text { Multifaceted } \\ \text { work }\end{array} & \begin{array}{l}\text { Demanding work } \\ \text { Imbalance between }\end{array} & \begin{array}{l}\text { shift work, heavy shifts on the weekends } \\ \text { the importance of anything else but patient contact } \\ \text { ever-increasing demands on knowledge }\end{array} \\ \begin{array}{ll}\text { (115 } \\ \text { utterances) }\end{array} & \begin{array}{l}\text { elderly people should live at home longer... But less } \\ \text { personnel who should manage to get more done } \\ \text { if the workload increases more } \\ \text { too unvaried tasks without challenges }\end{array}\end{array}$

Organizational Consequences of lack of resources

(96 utterances) resources Unsatisfying leadership too few personnel, not competent personnel permanent fixed-term employment contracts "that we don't get more personnel when the number of clients increases

constant changes, which have often not been considered to the very end either, you can't trust things the worker is of less and less importance [they] don't listen to the workers unfair distribution of work, does not apply to everyone

stress/always a rush during work too much of a rush with the clients sometimes sleep poorly; the job is in [my] thoughts... if... the stress increases more...

(65
utterances)

\subsection{Factors positively affecting work motivation}

The category "Work environment" (234 utterances), included the sub-categories "Satisfaction with colleagues" and "Satisfaction with leadership and organizational resources", generated the most frequent responses. Work environment as a motivational factor was due to both colleagues and leadership, as well as resources to carry out work tasks. Satisfaction with colleagues included good relationships, and a sense of belonging. It was essential to have a particular place in the work community. HCNs who felt that they were liked, conveyed a sense of wellbeing. Well-functioning teamwork was emphasized. It was considered effective and a product of reliable and supportive colleagues with good collaboration skills. Enjoyment and wellbeing at work led to work pleasure. However, the HCNs' own attitude to work was of 
importance for work motivation. Satisfaction with leadership included that the labour management trusted the HCNs; and allowed them to take responsibility and influence their work content, routines, work schedules, work quantity, and vacations. Another factor mentioned was to be able to perform other tasks for a change or supervise new colleagues. Furthermore, good supervisors, applying a supportive leadership style, including having a good attitude with workers and good dialogue skills were emphasized. If the necessary organizational resources were available, which were required to perform the job, it was possible to complete high quality work. This included appropriate work equipment, and good planning of work, for example functioning work schedules, sufficient staff, and sufficient time to perform client work, appropriate workload, and peace and quiet to perform work.

The category "Significance of the work" (161 utterances) generated the second highest number of responses and included the sub-categories "Meaningful work" and "Enriching client meetings". Home care work was described as both meaningful, in order to help clients in their everyday life, and also a work driven by inner motives to help. Home care work as a profession was perceived as being in line with the HCNs' own holistic view. Home care work was considered important, meaningful and necessary, allowing possibilities to make a difference in people's lives. An intrinsic motivation to help other people was emphasized; having the will, ability, and permission to help clients in their everyday life, and to bring them happiness. HCNs enjoyed working with the clients and cared for their well-being. Furthermore, home care work entailed recurrent social contacts; HCNs got to know their clients well and felt close to them. However, not only did the HCNs help the clients; the clients' welcoming reverberated positive feelings back to the HCNs.

The category "Stimulating challenges" (131 utterances), included the sub-categories "Multifaceted work" and "Competence and desire to develop", emphasized typical duties of the work. Home care nursing was described as both varying and challenging, being encouraged to use many different skills and to further education. Home care nursing comprised both responsibility and freedom. The ability to do shift work and the work content were brought up. The work was unpredictable and varying, with different tasks every day and work in different places, mostly in the clients' homes. There were challenging tasks and client situations, requiring both physical and mental power as well as social skills. According to HCNs, they had the work they desired and were educated for, allowing them to work in an interesting branch. Work experience and professional skills were emphasized. HCNs trusted themselves and had belief in their skills and competence. They felt strengthened by results of work done and success in problem solving. Likewise, they wanted to continue developing their professional skills and attend additional work education.

The category "External response" (77 utterances) gathered the fourth most frequent responses and yielded the sub-categories "Recognition from clients and relatives" and "Recognition from colleagues and management". Positive feedback received externally from others for work done seemed to be of importance to gain motivation to continue working. Feedback received from the clients appeared as appreciation, praise, and encouragement. A hearty welcome from the clients, who were grateful for getting help and a good care improved motivation. Likewise, recognition from relatives showing their 
thankfulness for good care were expressed. Positive feedback from colleagues as encouragement and displayed satisfaction were found to be important, as well as supervisors and employers expressing their appreciation.

Moreover, less frequently mentioned responses increasing motivation were "Income stability" (32 utterances), "Close relationships and leisure" (18 utterances), and "Sufficient health and energy" (6 utterances).

\subsection{Factors negatively affecting work motivation}

The most frequent responses negatively affecting work motivation yielded the category "Organizational work environment" (176 utterances), and the sub-categories "Lacking resources" and "Unsatisfactory leadership". Consequences of shortages in resources as well as unsatisfying leadership influenced the work environment. Due to a reduction in financial resources and optimization, worsening care conditions, resources not meeting the needs of care, and inequalities between work teams were revealed. HCNs stressed inadequate or lack of necessary work tools, inappropriate workspaces, and poor indoor air quality. Frequent changes caused concern, as they often occurred at short notice, and were perceived both difficult and burdensome. Changes were seen in existing responsibilities as well as in new tasks and new ways of working. Both incompetence among the permanent workers and difficulties in finding skilled staff were stated. Nevertheless, accessible skills among HCNs remained sometimes unused. Moreover, a negative effect on work motivation was a weak leadership. Significantly leaders' negative attitude towards workers, and their lack of response, support and appreciation. Insufficient dialogue between workers and leaders was emphasized, including poor information, work instructions and guidance at work. Leaders being inaccessible, escaping their responsibilities or making too high demands, sometimes without adequate follow-ups. Injustice in everyday work, unclear job descriptions, as well as poor work planning and scheduling were accentuated, in addition to HCNs not being involved in the work planning. Further hindrances stressed were unclear criteria and purposes of the home care work, and an overall unsystematic work organization.

The category "Time constraints" (144 utterances) gathered the second most responses and generated the sub-categories "Significant rush and stress" and "Negative consequences of time pressure". There was a constant time stress causing a negative strain. HCNs perceived their work pace as too high due to time pressure, leading to a considerable and sometimes unreasonable rush. Physical and mental stress were present in everyday work. Among some HCNs, the stress arose periodically, while others considered it a constant and extreme stress. Too many client visits a day and time pressure when driving from one client to another triggered the stress. HCNs were often behind the scheduled time. They experienced less time for completing tasks, and for listening to the clients. Consequently, tasks were left unfinished or undone, with the quality of work suffering and the workload perceived as too hard.

The category "Job characteristics" (119 utterances), yielded the sub-categories "A hard work" and "Lowered ambition", and had the third most frequent responses. The multifaceted nature of home care nursing included demanding challenges affecting the HCNs' energy and get-up-and-go-ahead spirit. Home 
care nursing as a solitary and highly demanding work requiring great responsibility felt burdensome. HCNs expressed a feeling of uncertainty and being unsatisfied. There were many client visits per day, with often new clients and new tasks. Additionally, the work environment was often non-ergonomic, and many clients were physically heavy to assist. Sometimes the work environment was unclean. The shift work was perceived as hard, and additionally home care nurses worked a lot of overtime. In addition, they experienced little opportunity to influence their working hours and schedule, as well as the work routines and job tasks. Not feeling involved in decision making was negatively affecting home care nurses' motivation. The amount of administrative work had increased during the last years. It was perceived as taking too much time from the client work, and some assignments were considered unnecessary. Unfinished administrative work was stressful, and besides, HCNs stated deficiencies in documentation, even among ordinary staff. Additionally, there were frequent staff changes with lots of new colleagues. The weather conditions of the seasons were at times challenging. Many kilometres were driven by car, sometimes in demanding weather and bad road conditions. Working in the clients' often very warm homes followed by driving in a cold car were conveyed. Alarming was that the already high workload was perceived as increasing, because of a higher amount of work, increasing requirements, and more complex clients with more challenging care needs. HCNs wanted to improve their skills, but at the same time, they experienced declining levels of energy and willingness. The work became an old habit, and the attitude and the feeling towards work became increasingly negative.

The category "Work community" was the fourth most frequently mentioned utterance, (74 utterances), and yielded the sub-categories "Negative atmosphere" and "Poor engagement". A poor work community, including a bad atmosphere and negative and tired colleagues, was negatively affecting work motivation. Poor cooperation and conflicts in the working group along with the complaining of others, arrogance, gossip, slander, and jealousy were brought up. In addition, a language barrier between Swedish and Finnish speakers was mentioned, although only by a few HCNs. Lack of commitment and motivation were expressed as poor work ethic and poor activity among the staff; colleagues being lazy, high usage of private mobile phones, and not participating in tasks other than client work. HCNs emphasized poor responsibility among colleagues when tasks were left undone, and colleagues were not helping each other even though needed. As a result, a loss of confidence in colleagues was seen.

Other factors negatively affecting work motivation, although mentioned less, were "Weakened health and energy" (35 utterances), "Feedback from clients and relatives" (23 utterances), "Salary level" (23 utterances), "Staff shortage" (19 utterances), "National controlled decrees" (6 utterances) and "Age" (1 utterance).

\subsection{Factors positively affecting occupational self-efficacy belief to continue working}

The most frequent response supporting one's belief to continue working until the expected retirement age yielded from the category "Own health" (140 utterances), with the sub-categories "A resource and a challenge" and "Health supporting activities". Overall, HCNs conveyed their health as an important 
resource in work life, worth investing effort in. The health was both a resource and a challenge. The current health and wellbeing provided belief to continue working among home care nurses with no existing health impairments, or when they were able to manage well with health challenges. However, hope for good physical and mental health to continue were expressed. Existing health declines were perceived as a challenge to continue working. Some HCNs felt anxious about their deteriorating health; they perceived worries about their future work ability and voiced the need to prioritize their health before continue working until the expected retirement age. However, HCNs declared an intention to and an interest in promoting and maintaining their health, by participation in rehabilitation programs, and with appropriate physical exercise, rest and eating habits. Some HCNs hoped for a better health after a forthcoming surgery. Only a few HCNs saw support actions as a demand in being capable to continue working.

The category "Workplace resources", received the second most responses (118 utterances), and yielded the sub-categories "Satisfactory organizational resources" and "Strong workplace community". Overall, well-organized work was in high demand, including both material resources, good leadership, and good relationships with colleagues. Having enough disposable HCNs, both temporary and skilled workers, and retaining existing workers using continuing employment agreements were emphasized. Moreover, supply of the ergonomic tools which are required and the ability to adapt the clients' homes for their care needs, as well as job training to cope with demanding clients were mentioned. A good leader was supportive, responsive, understanding and encouraging, showing appreciation for efforts made and treating workers equally. HCNs emphasized the importance of participation in work related matters, such as the influence over working hours, workload, work content and opportunities for job rotation. Employers noticing the age of the workers in a positive way was also emphasized to influence belief. Furthermore, the availability of modified tasks in line with current work ability was stressed, as well as the importance of qualitative occupational health care service. A strong work community was essential. Likable colleagues, who HCNs got on well with, produced job satisfaction. In well-functioning work teams, colleagues supported and helped each other. Sometimes, an even deeper friendship developed. However, the possibility to be able to switch to another work team in the case of poor work community was also highlighted.

The category "Meaning of the work" gathered the third most frequent responses (97 utterances) and generated the sub-categories "Satisfaction from work" and "Intrinsic motivation". The deeper meaning of the work comprised of the clients themselves, the work tasks, and a strong intrinsic motivation of the HCNs. HCNs liked their clients and were very pleased to work with them. The client relations provided social interaction and rewarding meetings that strengthened motivation. Moreover, HCNs were satisfied with the work tasks and their workplaces. HCNs enjoyed and got pleasure out of their work. A great intrinsic motivation and a strong desire to help and take care of people were emphasized. HCNs experienced their work as meaningful and highlighted the large amount of people in need of assistance. They stressed feelings of love for their work, and stated home care nursing as their dream profession. A work where their own work morale was essential. 
The category, "Nature of the work" (94 utterances) had the fourth most frequent responses and yielded the sub-categories "Job stability" and "Skilled in demanding work". The multifaceted and challenging home care work provided opportunities to develop and use professional skills, as well the fact that there are a large number of available positions within this field. The home care profession was stated as a stable work, since there is a continuous need of work staff, and future demand due to the changes in the society concerning more people living at home for longer. The sense of security to continue working within the same field and work team was also expressed. HCNs appreciated the multifaceted nature of home care. They experienced themselves as skilled, with confidence in managing the varying work tasks. They saw continued changes and work-related challenges as inspiration, as they were motivated to develop their own professional skills. However, HCNs longed for reasonable mental and physical workload, as well as for a better status for the home care work.

Furthermore, but in less degree, the categories "Family life and leisure" (35 utterances), "Joy of living and wisdom" (32 utterances), "Income needed" (18 utterances) and "Appreciation and feedback" (17 utterances) emerged. Two people had not thought about what provided them with belief to continue working.

\subsection{Factors negatively affecting occupational self-efficacy beliefs to continue working}

The category "Health-related decline" (145 utterances) gathered the most frequent responses, yielding the sub-categories "Current life and health" and "Future health challenges". Simply if the overall health remains; the HCNs did not see any hindrances to continue working until the expected retirement age. However, the current health and balance in life revealed challenges. HCNs brought up a long list of diagnosed diseases, such as mental health disorders, musculoskeletal diseases, and hypertension. Many reported aches and pains in the back, shoulders, knees, or fingers. Due to the current health limitations, HCNs expressed concerns and uncertainties of whether the current diseases will deteriorate, and about future illnesses. Along with physical decline, high mental strain, insomnia, reduced energy and weakened recovery caused uncertainty about the future. Moreover, the concern of close relatives' health was also stressed. However, only a few mentioned their ageing as a concern.

The second most frequent responses generated the category "Multifaceted work" (115 utterances), and the sub-categories "Demanding work" and "Imbalance between individual resources and demands". HCNs stated home care nursing as burdensome. The multifaceted and challenging nature of the work imposed high demands on balancing individual resources. The shift work was hard, with irregular and inconvenient working hours, intense, and composed of too many shifts without days off. Moreover, extended working days, frequent overtime and being asked to work at short notice were brought up. Increased work areas also entailed longer work trips and more travel time in the car. HCNs expressed discontent with the increased number of administrative tasks, sometimes at the expense of client work. An increased requirement on knowledge was experienced, and some HCNs stressed an inadequate knowledge level in relation to the requirements. Moreover, concerns about an imbalance between 
individual resources and work demands were emphasized. HCNs revealed an already heavy but still increasing physical and mental workload. There was an increase in the number of clients, often with more demanding care needs, and yet often less time for caring and assistance. Care giving in clients' homes, often with insufficient ergonomic tools, entailed physical heavy workload. Mentally challenging was the need to be constantly flexible at work, the already high and increasing work demands, as well as the uncertainty about future demands and an even greater workload. HCNs sometimes perceived too much responsibility and were concerned about the poor quality of the final home care being provided. Dealing with clients and relatives was also stated to be mentally challenging as well. In contrast, lack of challenges, personal development, and promotional opportunities also negatively affected belief in being able to continue working until retirement age.

The category "Organizational resources" gathered the third most frequent responses (96 utterances) and yielded the sub-categories "Consequences of lack of resources" and "Unsatisfying leadership". Lacking resources and economic savings were conveyed as staff reductions, understaffing, hiring freezes, despite the need of workforce, incompetent workers, and the continuous employment of temporary workers. Due to savings, involuntary team and workplace changes were forced. Home care nursing was exposed to frequent and continuous changes due to the organizational changes, reorganizations, and fusions of organizations. Many changes were considered irrational, causing either deterioration, or not achieving the expected results, and were mentally stressful and energy draining. Some changes were considered as uncontrollable, and the uncertainty and fear of losing one's job was revealed. Dissatisfaction with leadership and poor leadership skills were emphasized, decreasing HCNs' belief to work until the retirement age. Lack of support, appreciation, respect, justice and equality were disclosed, as well as unclear or missing information. HCNs experienced that they sometimes were not listened to, and that their supervisors had inadequate understanding of home care nursing. Moreover, excessive demands with no resources for realization were stressed, as well as poor and unfair work distribution.

The category "Work related strain" (65 utterances), which generated the sub-categories "Constantly present rush" and "Imminent threat of stress", had the fourth most frequent responses. A constant rush causing stress reactions was negatively affecting HCNs' belief to continue working until the expected retirement age. The hurry was an existing companion in the everyday work, perceived to be further increasing, and too hard. Some HCNs wanted to change work, because of the rush. Concerns about continuous stress was emphasized. Home care nurses expressed reduced stress tolerance, including thoughts about work interrupting their sleep, and that they were worried about future stress aggravated reactions.

In addition, categories with less responses were "Political and national decisions" (23 utterances), "Workplace community" (20 utterances), "Financial reasons" (18 utterances), "Retirement and family life" (7 utterances), "Lack of motivation" (7 utterances), and "Unemployment" (4 utterances). Four utterances stated that nothing could negatively affect their belief of continue working until the expected retirement age, and four people had never thought about it. 


\section{Discussion}

The aim of this study was to explore factors that positively and negatively affect ageing HCNs' work motivation and occupational self-efficacy belief to continue working until the expected retirement age. The findings showed that several factors concurrently affected both work motivation and self-efficacy belief. When the factors were well-functioning, they positively affected both motivation and self-efficacy belief, and when they were insufficient, they negatively affected either or both motivation and/or belief. Our results are supported by many findings from previous research on work motivation and prolonging work life in home care and health care sector among mixed aged $(8 ; 14)$ and older nurses $(38 ; 39 ; 40)$. Since our study included solely HCNs of 45 years and older, it conveys important knowledge about ageing HCNs. Although age management should include all age of workers, addressing ageing workers' needs might help to deal with the lack of skilled health care workers and to promote their work careers, receiving workers with better well-being and work ability (41).

HCNs perceived that their health highly affected their self-efficacy belief to continue working. Current health declines, and concerns about future deteriorations, caused uncertainty. Furthermore, the high physical and mental workload experienced, raised concerns regarding health and thoughts to change work field. Therefore, it is of great importance to obtain a balance between resources and demands. This is supported by earlier studies; unmanageable work demands in the nursing sector must be handled (14; 38). Considerations about individual health (42) and feelings of being worn-out influences older workers' decisions on whether to continue working $(38 ; 43)$. When having a physical form of work, poor health affecting the work ability may force the worker out of work $(44 ; 45)$. Self-rated health is considered a better predictor of extended working life among older health care personnel, compared to diagnosed diseases (43). Self-rated health is therefore an important predictor of work ability perceptions (46).

Self-rated health is highly affected by the workers' perceived job satisfaction (43), as well as having meaningful tasks (47). Perceived meaning of work might also moderate the negative effect of age on work ability (15). HCNs in our study emphasized the meaningfulness and satisfaction, both increasing work motivation and self-efficacy belief to continue working. The meaningfulness was considered as an intrinsic motivation for the home care nursing itself. These results are consistent with previous research $(12 ; 10 ; 14 ; 15 ; 5)$. Additionally, external response and recognition from employers, clients, and relatives increased work motivation in our study. Likewise, supportive colleagues, a good workplace community, and good teamwork improved both work motivation and belief to continue working. These results are also supported by earlier research $(8 ; 14 ; 38 ; 42)$. Nevertheless, intrinsic motivation is found superior to extrinsic motivators in maintaining job satisfaction (17). A recent systematic review and meta-analysis stressed the importance of focusing on organizational strategies enhancing intrinsic factors, through building a professional and workplace meaning, and value-driven strategies to improve job satisfaction (17). Job satisfaction is important when an ageing worker decides whether to continue working life (48; 17), and stated critical to relieve the shortage of nursing staff (17). Lack of motivation as a barrier to continue to work until retirement age was mentioned only a few times in our study, supporting that 
motivation does not generally decrease with age (10). To ensure the quality of home care, enhancing HCNs' intrinsic work motivation through meaningfulness of work is essential $(1 ; 8)$.

At a deeper level, the health lacks meaning without a meaning in life (49), and the meaningfulness of work itself and the work content emerged as essential values for HCNs in our study. A sustainable health can be achieved only when the human being is becoming aware of the deeper dimensions of health within herself/himself and is actively following the inner values which are leading her/him towards health (49). Health declines might entail new vital necessities. If health declines restrain the ability to continue working, a valuable issue in life may be lost. The familiar existence and the wholeness of life is lost, and a suffering arise (49). In this study, the care work, close to the clients, brought meaning to the HCNs' life. In the Nordic tradition of caritative caring, vitality is considered the inner essence of health and an important inner resource of health (50). The meaningfulness of life is significant to the vitality. The vitality emerges when a human being experiences that her/his activities are valuable, that she is valued as a human being, and that she is living in harmony with the meaning of life (49). In this study, the caring work close to the clients increased the meaningfulness of life, as well as the vitality. Belief in own capabilities, i.e. self-efficacy, can be understood as an expression for willpower and vitality, meaning that factors enhancing self-efficacy are also supposed to strengthen vitality. In this study, HCNs emphasized ill-health as a threat against own capability to continue working until expected retirement age. Therefore, the leaders' and organizations' responsibility for supporting occupational health remain extremely important; not only in general, but in a person-centered perspective (51).

Self-efficacy belief is found effective in promoting health behaviour change (52; 53); crucial for both motivation and actions towards health improving changes (53). Expected outcomes, goals rooted in one's values, benefits and losses from changing behaviour, and the perceived self-satisfaction influence one's health behaviour (53). People with high self-efficacy belief have the power to produce desired changes by their actions and will translate health knowledge into health enabling practices with minimal support. They have the incentive to act and persevere in the face of difficulties. Contrary, people with self-doubts about their efficacy, or belief that health habits are beyond their control, need considerable support and guidance to strengthen their perseverance, and to build progressive success through mastery experiences by overcoming challenging obstacles (53). Thus, the level of individual support needed depends on the level of the workers' self-efficacy belief. Self-efficacy can be developed by mastery experiences by overcoming challenging obstacles, modelling by seeing peers succeed, positive feedback, and group support and encouragement, until one starts believing in one's capabilities (54). Since self-efficacy is an important prognostic factor for work ability among HCNs, enhancing self-efficacy is recommended in workplace interventions to promote $\mathrm{HCNs}^{\prime}$ work ability, as well as focusing on other changeable factors such as physical job demands and musculoskeletal well-being (9).

Many positively and negatively affecting factors mentioned by the HCNs' in our study refer to their personal health and resources in relation to experienced work demands and resources. To influence the factors addressed and take actions to make a sustainable working life for the ageing HCNs, the leaders and the work organizations must be involved to succeed. They have the empowerment to make changes 
that on a long term influence the workers' ability to remain in working life (42; 39). The swAge model (42) is a new concrete tool for leaders and organizations, as well as for workers, to both identify risks and develop work issues that contribute to a sustainable working life, throughout the whole working career. Areas important to the HCNs in our study fits into the model and need to be considered by the supervisors and the organization; the health, and its relation to physical and mental work demands, leadership, development, meaningful work, workplace community, and social support. Due to the results in our study, leaders engaging in dialogues with HCNs, actively expressing feedback and support, and inviting HCNs to influence their work with their great knowledge, could facilitate HCNs' self-efficacy belief to continue working. Likewise, support and feedback from colleagues, and a wealthy work community provided selfefficacy belief in our study. According to the swAge model, social support should be reinforced by social inclusion in the work group (42). Despite the travelling character of home care work, it is therefore important that employers make opportunities for team and informal meetings among home care staff to strengthen the social relationships (14).

Even though the home care nursing was perceived as both mentally and physically challenging in our study, the autonomy, flexibility, and multifaceted character, conveyed both motivation and belief to continue working in conditions of balanced resources and demands. Similar factors have been found to contribute to HCNs' intention to continue working (14).

The HCNs in our study felt skilful in their work and were strengthened using their various skills and succeeding in challenges. Although a reduction in energy was perceived as a hindrance for one's own development, HCNs still wanted to face new challenges and develop in their work. Positively valued demands might have a motivational potential (55), since enough job resources are available (56). Among elderly care nurses it has been noticed that they want to improve the care being provided (38). Thus, HCNs should be offered opportunities for continuous education and development $(8 ; 14 ; 42 ; 57 ; 58)$, as well as the opportunity to influence the improvement of home care work. Earlier studies have confirmed, that by offering regular education to ageing workers, their self-efficacy can also improve $(59 ; 57)$.

The health is not only a personal matter; it is also a societal matter. Factors on individual, organizational and societal levels influence health and workers' intentions to remain in working life $(60 ; 39 ; 40 ; 53)$. Work organizations are responsible to arrange work in a way that supports workers (22). However, societal demands on increased workplace measures might further stress companies to implement strategies to retain older workers in work life $(42 ; 61 ; 62)$. Therefore, interventions enhancing working life must pay attention to the complexity of work life (42), and be performed in parallel on the different levels $(9 ; 53$; 42).

Still, the workers are responsible for taking care of their own health and lifestyle habits, as well as for their mind-set towards work, including their values, attitudes, motivation, and other personal factors (22). Nevertheless, both health and personal resources are always influenced by work related factors manoeuvred by the work organization. When a worker's resources are scarce, the work demands are experienced tougher, thus lowering the resources even more, and the worker might lack the energy to 
change the situation (63). According to a study exploring support after comprehensive vocational rehabilitation, workers' initiative greatly influenced the amount and kind of support received (63). However, the initiative to request support from occupational health care or supervisor might be a major challenge to a worker with already scarce resources. In these cases, it is important that employers together with occupational health care experts capture these workers to provide adequate support and actions.

However, due to high individual differences among ageing workers, they should not be considered as a homogenous group (13). They want to be seen as an unique person; also found important when an ageing worker decides whether to continue working life (48). Although positive aspects of ageing are publicized, negative attitudes against older workers are still present $(57 ; 61 ; 62)$. Notably, in our study only a few HCNs mentioned their ageing as a concern. Still, they wanted the employers to notice their age in a positive manner, not as a barrier. Changes of managers' attitudes to ageing workers is important, since managers can influence factors to improve ageing workers' working life (62). However, because all workers, all workplaces and work situations are unique, the solutions to improve working life must be individually adapted $(42 ; 40)$. Thus, also taking into consideration the factors improving work motivation and belief in capabilities to continue working. A good interplay and shared responsibility between the worker and the working environment, taking the workers' capacities and the work requirements into account to attain a good balance between individual resources and work demands, is needed for sustainable employment (64).

The employer is responsible for the promotion of workplace health trough creating prerequisites for a healthy work environment (49). An organization's focus only on profitability tend to draw on the human values. Fundamental to good care outcomes and a sustainable occupational health is that the leader meets the HCNs in a person-centred way with dignity, respect, and trust, and allows them to work in harmony with own values in an organizational culture where both the workers' and the clients' health and well-being as well as good relationships are in focus (51). The results in our study emphasize the value of good community and relations at the workplace to stimulate work motivation and belief to continue working. Experiencing community and a sense of belonging is generally an elixir of life for human beings (49), and therefore, also for the ageing HCNs, their motivation and belief to continue working.

\subsection{Methodological considerations}

Using a cross-sectional study, prevalence of multiple outcomes could be measured, and many participants could be reached at the same time (65). All HCNs in the chosen region, aged 45 years and older, were invited, and were considered as representatives of ageing workers in the home care sector. Another strength of this study was the use of multi-methods, including both qualitative and quantitative analysis of the research data. The manifest qualitative analysis provided a deeper knowledge and understanding of the issues $(32 ; 37)$. Moreover, the quantitatively measured frequencies of utterances gained reliability since the focus of HCNs' experiences was acknowledged (32). However, there are some limitations when using a cross-sectional study. The outcomes in the participants are measured 
concurrently, describing the phenomena at one specific time, and it is difficult to derive causal relationships (65). When using a questionnaire there is a risk of high numbers of dropouts. The response rate was $51 \%$, which could imply a possible bias of the outcome. In agreement with the close supervisors, who administered the survey, the use of paper-based and/or web-based questionnaire was decided. The response rate was slightly lower among the web-based respondents. Hence, some none-responding HCNs might have answered a paper-based survey. Moreover, the research data consisted of open-ended questions. The answers were often short, which despite manifest analysis, might have caused some interpretation bias (37). Therefore, we returned repeatedly to the meaning units as well as all the respondent's answers to check the entirety and the meaning $(32 ; 37)$. The response rate of the openended questions among the answering respondents was high ( $86-97 \%, n=202-227$ for each question), although the open-ended questions were placed last in quite a large-scaled survey. This indicated that HCNs had an interest to articulate their work motivation and belief in their capabilities to continue working. Another strength was that the findings not only highlighted factors that motivates HCNs to perform work tasks, but also an intrinsic motivation to care, reflected by internal feelings of care for clients and a deeper meaning of the work.

The HCNs' responses were either in Swedish or Finnish language. None of the researchers had Finnish as their mother tongue, although two of them mastered Finnish well. In the case of linguistic doubts, a person with Finnish as their mother tongue, also skilled in health care, was consulted. The researchers' pre-understanding consisted of long experience in health care, occupational health service and rehabilitation as well as experience in qualitative and quantitative research. To minimize the preunderstanding, the qualitative data analysis followed a structured procedure in several steps $(32 ; 37)$. Dependability was established by repeatedly going back to the encoding, verifying the encoding to the meaning units and the open-ended answers, and checking the reliability of the categories $(32 ; 37)$. Notes about the encoding were made throughout the analysis process. To increase conformability, triangulation between researchers was used. Quotations were used to support authenticity in presented categories (Table 2) (32). Moreover, our study addressed the explicit views of the ageing HCNs, in the context of both rural and urban areas, including home care services conducted by municipalities, cities, and social- and health services consortiums. The categories that emerged through manifest content analysis were considered logical and answering the purpose of the study. The findings from our study can likely be transferred to other Nordic countries, due to their similarities in home care service (5). Despite home care including distinct elements concerning care in clients' homes; the results might be transferable to ageing workers in other nursing contexts $(32 ; 37)$. Due to the high number of participants, a generalization to a broader population of ageing HCNs might be applicable.

\subsection{Practical implications}

The results of this study convey important understandings of the ageing HCNs' views of work motivation and occupational self-efficacy belief to continue working until expected retirement age. By supporting HCNs' health and emphasizing the meaningfulness and positive aspects of the work, offering overcoming challenges and learning opportunities, the HCNs' work motivation and belief to continue 
working can be strengthened. This information could be used by supervisors, organizational management, occupational health personnel, safety personnel, and by HCNs themselves, to consciously reflect on and develop a sustainable work life for ageing HCNs. Addressing the needs of ageing HCNs could also help employers deal with the lack of workers in the home care sector. In turn, employers could receive more workers with better well-being and with possibly longer work careers.

\section{Conclusions}

Home care work was perceived as meaningful and stimulating, and through highlighting these positive aspects together with strengthening the work community, both work motivation and occupational selfefficacy belief to continue working might be facilitated. The perceived health highly affected the selfefficacy belief to continue working, emphasizing that work related demands must be balanced against the workers' resources, in combination with a healthy leadership. Ageing was not perceived to be a concern; HCNs still wanted challenges, and desired to develop work related skills. The results convey information to supervisors, organizational management, safety staff, labour unions and the ageing workers about important factors where intervention is needed, as well as factors that create good conditions, to make a sustainable working life for ageing HCNs, and thereby improve the ability to retain $\mathrm{HCNs}$, as well as attract new staff to home care.

\section{Abbreviations}

HCNs: Home care nurses

\section{Declarations}

\section{Ethical approval and consent to participate}

The study was carried out with the approval of the Board for Research Ethics at Åbo Akademi University, Turku, Finland (dated April 12, 2018). All methods were performed in accordance with the ethical guidelines outlined in the Declaration of Helsinki and delineated by the Finnish National Board on Research Integrity 2012. The participants received written information about the aim of the study, that participation was anonymous and voluntary, and that participants had the right to withdraw at any time. The participants provided informed consent to participate by answering the questionnaire.

\section{Consent for publication}

Not applicable.

\section{Availability of data and materials}

The data is not publicly available but could be requested from corresponding author after ethical approval to take part of the dataset. 


\section{Competing interest}

The authors declare that they have no competing interests.

\section{Funding}

No external funding.

\section{Authors' contributions}

SW: study design, data collection and analysis, interpreting the analysis, drafting the manuscript. AFW: study design, interpreting the analysis, involved in drafting the manuscript. LF: study design, interpreting the analysis, involved in drafting the manuscript. All authors read and approved the final manuscript.

\section{Acknowledgements}

Thanks to XXX, for help with the Finnish-Swedish translations of the open-ended questions and in linguistic doubts.

\section{References}

1. Rest KD, Trautsamwieser A, Hirsch P. Trends and risks in home health care. JHLSCM. 2012;2(1):3453; doi:10.1108/20426741211225993.

2. Genet N, Boerma W, Kroneman M, Hutchinson A, Saltman RB (Eds). Home care across Europe. Current structure and future challenges. Copenhagen: World Health Organization; 2012. 27th Observatory Studies Series. https://www.euro.who.int/_data/assets/pdf_file/0008/181799/e96757.pdf. Accessed 21 Apr 2021.

3. Vehko T, Sinervo T, Josefsson K. Henkilöstön hyvinvointi vanhuspalveluissa - Kotihoidon kehitys huolestuttava (In Finnish; The welfare of staff in old-age dependency services - Home care development concerns). Helsinki: Terveyden ja hyvinvoinnin laitos; 2017. Tutkimuksesta tiiviisti 11. Accessed 21 Apr 2021.

4. The EU in the world. 2016 edition. Luxembourg: Publications Office of the European Union; 2016. Eurostat. https://ec.europa.eu/eurostat/documents/3217494/7589036/KS-EX-16-001-ENN.pdf/bcacb30c-0be9-4c2e-a06d-4b1daead493e. Accessed 21 Apr 2021.

5. Kröger T, van Aerschot L, Puthenparambil JM. Hoivatyö muutoksessa: Suomalainen vanhustyö pohjoismaisessa vertailussa (In Finnish; Nursing in change - Finnish eldercare in Nordic comparison). YFI Publications 6. Jyväskylä: University of Jyväskylä; 2018. https://jyx.jyu.fi/bitstream/handle/123456789/57183/978-951-39-7372-8.pdf? sequence=1\&isAllowed=y. Accessed 21 Apr 2021.

6. Employment outlook by occupation. Occupational Barometer. Ministry of Economic Affairs and Employment of Finland, Centre for Economic Development Transport and the Environment, TE services - Public employment and business services. 3; 2020. 
https://www.ammattibarometri.fi/kartta2.asp?vuosi=20i\&ammattikoodi=5322\&kieli=en. Accessed 23 Mar 2020.

7. Rostgaard T, Mattiessen M, Kröger T, Mathews J, Strandell R, Stranz A, et al. Changes in Nordic care work and their effects on work-related problems for workers in long-term care. Copenhagen: Transforming Care Conference. VIVE - The Danish Centre for Social Science Research; 2019. http://www.transforming-care.net/wp-content/uploads/2019/06/Tine-Rostgaard-Work-tasks-andproblems-TCC-June-24-26th-2019.pdf. Accessed 23 Mar 2020.

8. Toode K, Routasalo P, Suominen T. Work motivation of nurses: A literature review. IJNS. 2011;48:246-57; doi:10.1016/j.jjnurstu.2010.09.013.

9. Larsson A, Karlqvist L, Westerberg M, Gard G. Identifying work ability promoting factors for home care aides and assistant nurses. BMC Musculoskelet Disor. 2012;13:1-11; doi:10.1186/1471-247413-1.

10. Boumans NPG, de Jong AHJ, Janssen SM. Age-differences in work motivation and job satisfaction, the influence of age on the relationships between work characteristics and workers' outcomes. Int $J$ Aging Hum Dev. 2011;73(4): 331-350.

11. Deci EL, Connell JP, Ryan RM. Self-determination in a work organization. J Appl Psychol. 1989;74(4):580-90; doi:0021-9010/89/\$00.75.

12. Van Den Berg P. Characteristics of the work environment related to older employees' willingness to continue working: Intrinsic motivation as a mediator. Psychol Rep. 2011;109(1):174-86; doi:10.2466/01.09.10.PR0.109.4.174-186.

13. Guglielmi D, Avanzi L, Chiesa R, Mariani MG, Bruni I, Depolo M. Positive aging in demanding workplaces: The gain cycle between job satisfaction and work engagement. Front Psychol. 2016;7:1224; doi:10.3389/fpsyg.2016.01224.

14. Tourangeau A, Patterson E, Rowe A, Saari M, Thomson H, Macdonald G, et al. Factors influencing home care nurse intention to remain employed. Nurs Manag. 2014;22:1015-26; doi:10.1111/jonm.12104.

15. Converso D, Sottimano I, Guidetti G, Loera B, Cortini M, Viotti S. Aging and work ability: The moderating role of job resources and personal resources. Front Psychol. 2018;2262(8):1-12; doi:10.3389/fpsyg.2017.02262.

16. Schalk R, van Veldhoven M, de Lange AH, De Witte H, Kraus K, Stamov-Rossnagel $C$ et al. Moving European research on work and ageing forward: Overview and agenda. Eur J Work Organ Psychol. 2010;19(1):76-101; doi:10.1080/13594320802674629.

17. Niskala J, Kanste O, Tomietto M, Miettunen J, Tuomikoski A-M, Kyngäs H, Mikkonen K. Interventions to improve nurses' job satisfaction: A systematic review and meta-analysis. J Adv Nurs. 2020 Jul;76(7):1498-1508; doi:10.1111/jan.14342.

18. Crawford JO, Davis A, Cowie H, Dixon K, Graveling R, Belin A, et al. (Eds). The ageing workforce: implications for occupational safety and health. A research review. Luxembourg: European Agency for Safety and Health at Work; 2016. Publications Office of the European Union. 
https://osha.europa.eu/en/publications/ageing-workforce-implications-occupational-safety-andhealth-research-review. Accessed 16 Mar 2021.

19. Boot C, Deeg D, Abma T, Rijs K, van der Pas S, van Tilburg T et al. Predictors of having paid work in older workers with and without chronic disease: A 3-year prospective cohort study. J Occup Rehabil. 2014;24:563-572; doi:10.1007/s10926-013-9489-y.

20. Van den Berg TIJ, Elders LAM, de Zwart BCH, Burdorf A. The effects of work-related and individual factors on the Work Ability Index: a systematic review. Occup Environ Med. 2009 Apr;66(4):211-20; doi:10.1136/oem.2008.039883.

21. Leijten F, Van den Heuvel S, Ybema JF, van der Beek J, Robroek S, Burdorf A. The influence of chronic health problems on work ability and productivity at work: a longitudinal study among older employees. Scand J Work Environ Health. 2014;40(5):473-82; doi:10.5271/sjweh.3444.

22. Ilmarinen J, Ilmarinen V. Work ability and aging. In: Finkelstein LM, Truxillo DM, Fraccaroli F, Kanfer R, editors. Facing the challenges of a multi-age workforce: A use-inspired approach. s.I.: SIOP organizational frontiers series. New York: Routledge; 2015, p. 134-156.

23. Cloostermans L, Bekkers MA, Uiters E, Proper KI. The effectiveness of interventions for ageing workers on (early) retirement, work ability and productivity: A systematic review. Int Arch Occ Env Hea. 2015;88:521-32; doi:10.1007/s00420-014-0969-y.

24. Bakker AB, Demerouti E. Job Demands-Resources Theory: Taking stock and looking forward. J Occup Health Psychol. 2017 Jul;22(3):273-85; doi:10.1037/ocp0000056.

25. Cetin F, Askun D. The effect of occupational self-efficacy on work performance through intrinsic work motivation. Manag Res Rev. 2018; 41(2):186-201; doi:10.1108/MRR-03-2017-0062.

26. Paggi ME, Jopp DS. Outcomes of occupational self-efficacy in older workers. Int J Ageing Hum Dev. 2015;80(4):357-78; doi:10.1177/0091415015607640.

27. Salanova M, Llorens S, Schaufeli WB. Yes, I can, I feel good, and I just do it! On gain cycles and spirals of efficacy beliefs, affect, and engagement. Appl Psychol Int Rev. 2011;60(2):255-85; doi:10.1111/j.1464-0597.2010.00435.x.

28. Rigotti T, Schyns B, Mohr G. A short version of the occupational self-efficacy scale. Structural and construct validity across five countries. JCA. 2008;16(2):238-55; doi:10.1177/1069072707305763.

29. Bandura A. Self-efficacy: the exercise of control. New York: W.H. Freeman \& Company; 1997.

30. Fullemann D, Gregor JJ, Brauchli R, Bauer GF. The key role of shared participation in changing occupational self-efficacy through stress management courses. J Occup Organ Psych. 2015;88:490510; doi:10.1111/joop.12124.

31. Wallin S, Rauhala A, Fjellman-Wiklund A, Nyman P, Fagerström L. Occupational self-efficacy and work engagement associated with work ability among an ageing work force: a cross-sectional study. Work. 2021; Accepted.

32. Kyngäs $H$, Mikkonen $K$, Kääriäinen $M$, editors. The application of content analysis in nursing science research. Switzerland: Springer; 2020. 
33. Ilmarinen J. Ageing workers. Occupat Environ Med. 2001;58(8):546-52; doi:10.1136/oem.58.8.546.

34. Tuomi K, Ilmarinen J, Jahkola A, Katajarinne L, Tulkki A. Work Ability Index. 2nd revised edition. Helsinki: Finnish Institute of Occupational Health; 1998.

35. Schaufeli WB, Bakker AB, Salanova M. The measurement of work engagement with a short questionnaire. A cross-national study. Educ Psychol Meas 2006;66(4):701-16; doi:10.1177/0013164405282471.

36. Regnault $A$, Willgross $T$, Barbic $S$ et al. Towards the use of mixed methods inquiry as best practice in health outcomes research. J Patient Rep Outcomes. 2018;2:19; doi:10.1186/s41687-018-0043-8.

37. Graneheim UH, Lundman B. Qualitative content analysis in nursing research: concepts, procedures and measures to achieve trustworthiness. Nurs Edu Today. 2004;24:105-12; doi:10.1016/j.nedt.2003.10.00.

38. Gyllensten K, Wentz KAH, Håkansson C, Hagberg M. Older assistant nurses' motivation for a full or extended working life. Ageing Soc. 2018;1-15; doi:10.1017/S0144686X18000740.

39. Warburton J, Moore ML, Clune SJ, Hodgkin SP. Extrinsic and intrinsic factors impacting on the retention of older rural healthcare workers in the north Victorian public sector: a qualitative study. Rural Remote Health. 2014;14(3):2721.

40. Markowski M, Cleaver K, Weldon SM. An integrative review of the factors influencing older nurses' timing of retirement. J Adv Nursing. 2020;76:2266-85; doi:10.1111/jan.14442.

41. Merkel S, Ruokolainen M, Holman D. Challenges and practices in promoting (ageing) employees working career in the health care sector - case studies from Germany, Finland and the UK. BMC Health Serv Res. 2019;19:918; doi:10.1186/s12913-019-4655-3.

42. Nilsson K. A sustainable working life for all ages - The swAge-model. Appl Ergon. 2020;86:103082; doi:10.1016/j.apergo.2020.103082.

43. Nilsson K, Rignell Hydbom A, Rylander L. How are self-related health and diagnosed disease related to early or deferred retirement? A cross-sectional study of employees aged 55-64. BMC Public Health. 2016;16:886; doi:10.1186/s12889-016-3438-6.

44. Andersen LL, Jensen PH, Sundstrup E. Barriers and opportunities for prolonging working life across different occupational groups: the SeniorWorkingLife study. Eur J Public Health. 2019;30(2):241-6; doi:10.1093/eurpub/ckz146.

45. Poulsen OM, Fridriksson JF, Tomasson K, Midtsundstad T, Mehlund IS, Hilsen Al, et al. Working environment and work retention. TemaNord. 2017;559. Copenhagen: Nordic Council of Ministers. http://norden.diva-portal.org/smash/record.jsf?pid=diva2\%3A1167099\&dswid=8650. Accessed 9 Feb 2021.

46. McGonagle AK., Fisher GG., Barnes-Farrell JL, Grosch JW. Individual and work factors related to perceived work ability and labor force outcomes. J Appl Psychol. 2015;100(2):376-98; doi:10.1037/a0037974.

47. Doyle YG, McKee M, Sherriff M. A model of successful ageing in British populations. Eur J Public Health. 2012;22(1):71-6; doi:10.1093/eurpub/ckq132. 
48. Nilsson K. The influence of work environmental and motivation factors on seniors' attitudes to an extended working life or to retire. A cross sectional study with employees 55-74 years of age. JSS. 2017;5:30-41; doi:10.4236/jss.2017.57003.

49. Wärnå-Furu C, editor. Hälsans praxis (In Swedish; Health practices). Stockholm: Liber; 2014.

50. Fagerström, L. Livskraft och livshållning (In Swedish; Vitality and attitude to life). In: Wiklund Gustin L, Bergbom I. Vårdvetenskapliga begrepp i teori och praktik. Lund: Studentlitteratur; 2012.

51. Salmela S, Koskinen C, Eriksson K. Nurse leaders as managers of ethically sustainable caring cultures. J Adv Nurs. 2017 Apr;73(4):871-82; doi: 10.1111/jan.13184.

52. Skeeran P, Maki A, Montanaro E, Avishai A, Bryan A, Klein WMP et al. The impact of changing attitudes, norms, and self-efficacy on health-related intentions and behavior: a meta-analysis. Health Psychol. 2016;35(11):1178-88; doi:10.1037/HEA0000387.

53. Bandura A. Health Promotion by Social Cognitive Means. Health Education \& Behavior. 2004 Apr;31(2):143 - 64; doi: 10.1177/1090198104263660.

54. Bandura A. On the functional properties of perceived self-efficacy revisited. J Manag. 2012;38(1):944; doi:10.1177/0149206311410606.

55. Schaufeli WB, Taris TW. A critical review of the Job Demands-Resources Model: Implications for improving work and health. In: Bridging Occupational, Organizational and Public Health. Dordrecht: Springer; 2014;43-68; doi:10.1007/978-94-007-5640-3_4.

56. Bakker AB, Sanz-Vergel AI. Weekly work engagement and flourishing: The role of hindrance and challenge job demands. J Vocat Behav. 2013;83:397-409; doi:10.1016/j.jvb.2013.06.008.

57. Van der Heijden B, Peeters M, Le Blanc P, van Breukelen J. Job characteristics and experience as predictor of occupational turnover intention and occupational turnover in the European nursing sector. J Vocat Behav. 2018;108:108-20; doi:10.1016/j.jvb.2018.06.008.

58. Andersen LL, Thorsen SV, Larsen M, Sundstrup E, Boot CRL, Rugulies R. Work factors facilitating working beyond state pension age: Prospective cohort study with register follow-up. Scand J Work Environ Health. 2021;47(1):15-21; doi:10.5271/sjweh.3904.

59. Hsu LL, Chang WH, Hsieh SI. The effects of scenario-based simulation course training on nurses' communication competence and self-efficacy: A randomized controlled trial. J Prof Nurs. 2015 JanFeb;31(1):37-49; doi: 10.1016/j.profnurs.2014.05.007.

60. Halter M, Boiko O, Pelone F, Beighton C, Harris R, Gale J, et al. The determinants and consequenses of adult nursing staff turnover: a systematic review of systematic reviews. BMC Health Serv Res. 2017 Dec 15;17(1):824; doi: 10.1186/s12913-017-2707-0.

61. Widell Blomé M, Borell J, Håkansson C, Nilsson K. Attitudes toward elderly workers and perceptions of integrated age management practices. Int J Occup Saf Ergon. 2020 Mar;26(1):112-20; doi: 10.1080/10803548.2018.1514135.

62. Nilsson K. Managers' attitudes to their older employees: A cross-sectional study. Work. 2018;59:4958; doi:10.1016/j.profnurs.2014.05.007. 
63. Wallin S, Fjellman-Wiklund A. Act with respect: views of supportive actions for older workers after completion of comprehensive vocational rehabilitation services. Work. 2019;62(4): 585-98; doi:10.3233/WOR-192896.

64. Oakman J, Neupane S, Proper KI, Kinsman N, Nygård CH. Workplace interventions to improve work ability: A systematic review and meta-analysis of their effects. Scand J Work Environ Health. 2018;44(2):134-6; doi:10.5271/sjweh.3685.

65. Cummings C. Cross-sectional design. In: Allen M, editor. The SAGE Encyclopedia of Communication Research. Los Angeles: SAGE; 2017. p. 315-17.

\section{Figures}

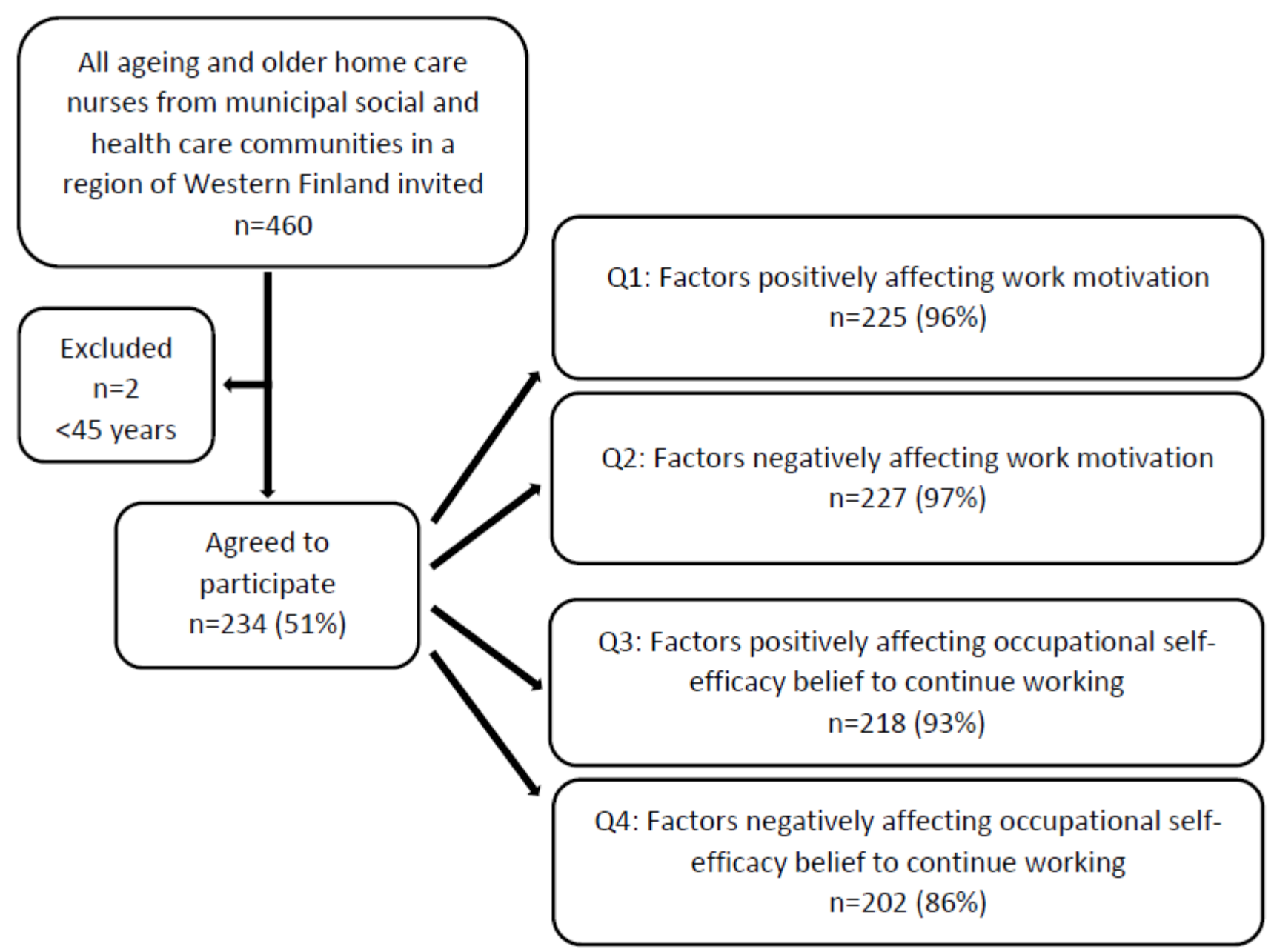

\section{Figure 1}

Flowchart of the study population 
Work motivation

(659 utterances)
Occupational self-efficacy belief to continue

working until the retirement age

(553 utterances)

$\begin{array}{ll}* \text { *Work environment } & 36 \% \\ \text { *Significance of the work } & 24 \% \\ { }^{*} \text { Stimulating challenges } & 20 \% \\ \text { *External response } & 12 \% \\ \text { Income stability } & 5 \% \\ \text { Close relationships and leisure } & 3 \% \\ \text { Sufficient health and energy } & 1 \%\end{array}$

* Organizational work environment

*Time constraints

*Job characteristics

*Work community

Weakened health and energy

Feedback from clients and relatives

Salary level

Staff shortage

National controlled decrees

Age

(620 utterances)
$0,2 \%$
POSITIVELY

AFFECTING
$25 \%$

$21 \%$

$18 \%$

$17 \%$

$6 \%$

$6 \%$

$3 \%$

$3 \%$

$\begin{array}{ll}\text { Family life and leisure } & 6 \% \\ \text { Joy of living and wisdom } & 6 \% \\ \text { Income needed } & 3 \% \\ \text { Appreciation and feedback } & 3 \%\end{array}$

*Health-related decline $\quad 29 \%$

*Multifaceted work 23\%

*Organizational resources $\quad 19 \%$

*Work related strain $\quad 13 \%$

Political and national decisions $\quad 5 \%$

Workplace community $\quad 4 \%$

Low income $\quad 4 \%$

Retirement and family life $\quad 1 \%$

Lack of motivation $\quad 1 \%$

Unemployment $\quad 1 \%$

NEGATIVELY

(507 utterances)

* Categories with most responses, closer described in text

\section{Figure 2}

Categories of positively and negatively affecting aspects of work motivation and self-efficacy belief

\section{Supplementary Files}

This is a list of supplementary files associated with this preprint. Click to download.

- AdditionalFile1.OpenendedquestionstranslatedEnglish.docx 